\title{
Csilla Schell
}

\section{Zur Schriftlichkeit der unteren Bevölkerungsschichten um die Jahrhundertwende Briefe im Ersten Weltkrieg}

\author{
Literacy of lower social classes at the turn of the century: \\ Letters in the First World War
}

\begin{abstract}
The paper discusses the literacy of lower classes in the last decades of the AustroHungarian Empire and focuses on the correspondence of the First World War. Besides briefly reviewing the general contexts for the literacy of lower social classes (education, legislation), the paper discusses language/ethnicity issues as well. By summarizing linguistic remarks from selected research papers, the author underlines that the large number of letters was due to the increased need for communication and these pieces of writing reflect the literacy and the language of the masses; consequently, wartime correspondence is an accurate reflection of the communication of lower social classes.
\end{abstract}

Keywords: Popular Literacy, World War I, Letter, Schooling, Writing

Auf einem Archivfoto in der dreibändigen Buchreihe der „Alten Budaörser Familien" ist im Bericht der Familie Deigner der Soldat Leopold Deigner zu sehen, zusammen mit einem Kameraden in einer Schanze stehend (Abb. Nr. 1). Das Bild zeigt keine spontane, sondern eine inszenierte Szene: die beiden Männer posieren in voller Ausrüstung und in selbstbewusster Stellung. Der genaue Transportweg des Bildes ist nicht überliefert, aber sehr wahrscheinlich wurde es nicht zur eigenen Erinnerung, sondern für die Daheimgebliebenen verfertigt und seinerzeit in die Heimat verschickt. ${ }^{1}$

1 Leopold Deigner Sen. wurde 1896 in Budaörs geboren. Er beendete 1911 seine dreijährige Lehre bei seinem Meister, dem Altofener Kammmacher Komáromi. Er kämpfte im Ersten Weltkrieg und war anderthalb Jahre in russischer Kriegsgefangenschaft. 1919 machte er sich selbständig und bis zur Vertreibung (1946) gab der Kammmacher-Altmeister das Handwerk jungen Leuten weiter. Deigner 2011, sowie mündl. Auskunft von Leopold

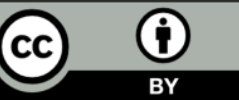




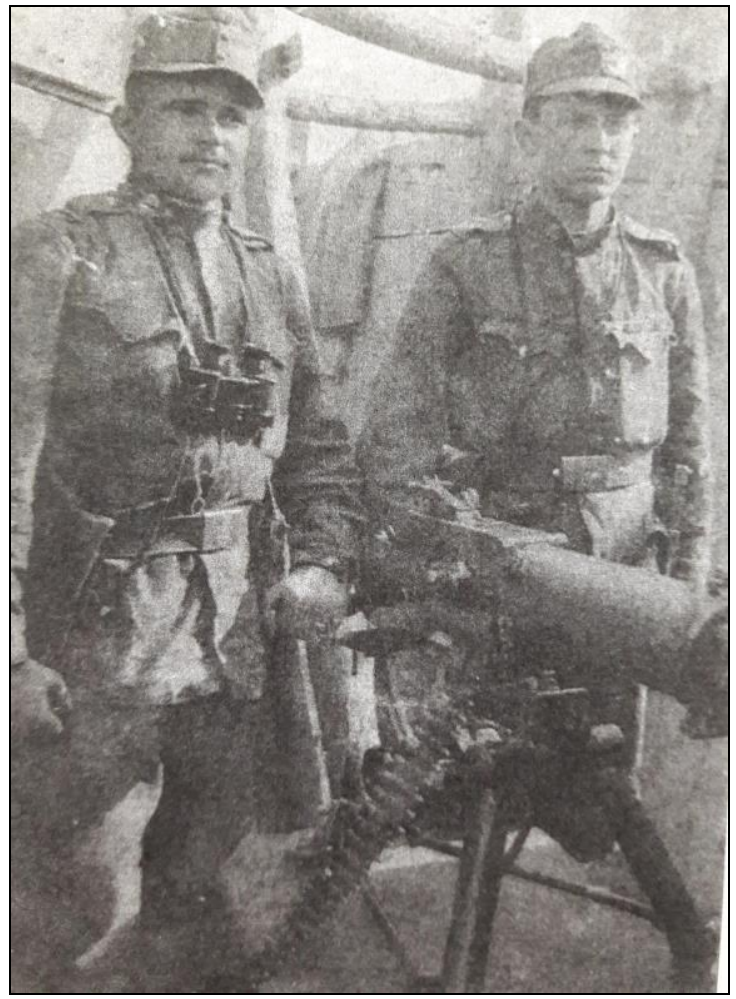

Abb. Nr. 1: Archivfoto. Quelle: Deigner 2011: 22.

Leopold Deigner hat den Ersten Weltkrieg und die Kriegsgefangenschaft überlebt - sein Name ist nicht unter den sieben Deigners, von denen auch der Älteste zum Kriegsende erst 32 Jahre alt war, auf der Liste der MarmorGedenktafel in Budaörs zu lesen. Das 1925 durch Spenden der Bevölkerung erstellte Denkmal im Budaörser Kirchgarten erinnert heute noch an die 368 Gefallenen. Die Statue zeigt einen in Christus' Armen sterbenden Mann - ein Soldat des 32-sten Regiments, denn in dieser Einheit dienten die meisten Budaörser, die v.a. an den galizischen und italienischen Fronten ihren Dienst leisteten. ${ }^{2}$ Manche Budaörser wurden am Ende des Krieges mit einem Helden-Ordenskreuz ausgezeichnet. Auch Leopold Deigner hätte, so ist in der Familienüberlieferung zu lesen, einen Vitéz-Orden bekommen - aller-

Deigner Jun. (geb. 1931 in Budaörs, heute wohnhaft in Brackenheim); IVDE Freiburg, 15.03.2020

2 Zur Geschichte des Denkmals vgl. http://budaors.varosom.hu/latnivalok/szobrok/Hosiemlekmuvek.html 
Zur Schiftlichkeit der unteren Bevölkerungsschichten...

dings nur unter der Bedingung, dass er seinen Namen magyarisiert, was er jedoch verweigerte. ${ }^{3}$

Bei den Deigners blieben m.W. keine Spuren einer Korrespondenz mit den Daheimgebliebenen erhalten. Anders bei der Familie Hauser, ebenfalls aus Budaörs. An einen Lőrinc (Lorenz) Hauser ist (mindestens) ein Brief überliefert. Den Brief vom 4. April 1917 schrieb seine Ehefrau Hauser Lőrincné an ihn in die Gefangenschaft. Erhalten ist der in deutscher Sprache geschriebene Brief nur durch den Umstand, dass er durch die k.u.k. Zensur in Budapest konfisziert und/oder kopiert wurde. Der beanstandete Brief gehörte zu jenen Tausenden, mittels derer monatlich „Meldungen zur Stimmungslage" von der Zensurstelle der Monarchie erstellt worden waren und demzufolge durch die „Zensurkommission für Korrespondenzen an Kriegsgefangene" überliefert sind. Der Nachweis dieser Quelle ist im einschlägigen Aufsatz von Péter Hanák zu finden. ${ }^{4}$

Hanák richtete die Aufmerksamkeit in Ungarn als Erster auf den hohen Quellenwert der Briefe aus der Zeit des Ersten Weltkrieges und leistete somit nicht nur für die ungarische historiographische Erforschung der Feldpostbriefe Pionierarbeit, ${ }^{5}$ sondern - für unseren Zusammenhang hier noch wichtiger - für die der Volks-Schriftlichkeit oder popularen Schriftlichkeit (népi irásbeliség). Hanák erachtete die Briefe als hochrelevante Dokumente, da wir für diese Zeit

„über wenig zuverlässige Quellen verfügen, aus denen man die Anschauungen, Gedanken, Gefühle, mit einem Wort die Mentalität des Volkes - der Leib-

3 Deigner Jun. 15.03.2020, mündliche Mitteilung. Die Deigners waren nicht die einzigen in Budaörs, die die Namensmagyarisierung ablehnten. Auch bei der Familie Ritter hatte der Vater anstatt des für die Kriegsverletzungen angebotenen Vitéz-Ordens einen Gewerbeschein gewählt. Ritter hausierte zunächst mit Stoffen und Tüchern und später gründete er ein kleines, aber rentables Unternehmen, das er bis zu Vertreibung der Budaörser betrieb. Schriftliche Auskunft von seinem Enkel, Andreas Ritter Schwetzingen, IVDE Freiburg.

4 Hanák 1973: 85.

5 Hanák untersuchte im Archiv der Militärgeschichte von Wien und Budapest jeweils die durch die Zensurstellen und Zensurkommission zurückgehaltenen Postkarten und Briefe. Diese betrugen in den Jahren 1917 und 1918 etwa 1,5 bis 5 Prozent der gesamten Korrespondenz, bei einer Postmenge von 8-10 Millionen in den Jahren 1916-1918. Die Zensurgruppen wurden nach Nationen und Sprachen zusammengestellt. Es zensierten etwa 1000 Zensoren täglich den Schriftstrom. In den ersten Jahren forschte die Kommission nach Spuren der Monarchiefeindlichkeit, von Hochverrat und Desertion. Ab April 1917 widmete sich das Zensurkommando jedoch verstärkt dem politischen Stimmungsbild in den Briefen, u.a. zu den Auswirkungen der russischen Revolution. 
eigenen, der armen bäuerlichen Schichten, Arbeiter - aus eigener Erzählung, aus dem Selbstzeugnis kennen lernen können. “6

Demzufolge versuchte er in seinem Beitrag die Mentalität des Volkes „ohne einmischende Deutung der Vermittler" anhand der Briefe nachzuzeichnen. V.a. die Abdrücke der sozialen Unzufriedenheit und die arm-reich Gegenüberstellungen werden in seiner Darstellung herausgearbeitet; teilweise werden die Briefe der Bauern und der Arbeiter gegenübergestellt, zugunsten der Letzteren.

Seine Analyse zum politischen Inhalt der Briefe liest sich, insbesondere bei den Arbeiterbriefen, als Abbildung der politischen Emanzipation der unteren Schichten, v.a. der Arbeiter. Es wird anhand der Quellen nachgezeichnet, wie die Arbeiter „zum Bewusstsein gekommen“ seien. (Einen vergleichbaren Ansatz verfolgte auch Tibor Szenti, der besonders auf die Emanzipation der Soldaten gegenüber ihren Vorgesetzten, den Offizieren abhebt.) $)^{7}$ Hanák betont unter anderem, dass dieser ,allmählich reifende Prozess" nicht nur ein ungarisches Phänomen sei. ${ }^{8}$ Das schlage sich in einem Stimmungsbericht aus dem Jahr 1918 nieder: „Der Sozialismus scheint in den Arbeiterschichten immer mehr Boden zu gewinnen, wobei [...] diesbezüglich keine Unterschiede in der Stimmung je nach Nationalität der Briefschreiber zu beobachten" seien. ${ }^{9}$ In diesem Zusammenhang kommt nach einer tschechischen und slowakischen Frau unsere bereits erwähnte Budaörser Schwäbin Frau Hauser zu Wort. Sie würde, so Hanák, die gesellschaftliche Hierarchie auch gerne umdrehen:

„»die Barone, Herzöge, Grafen, Könige und der Kaiser haben von dieser Armut nichts probiert, sonst hätten sie die Schinderei beendet... diese hohen Herrschaften müssten einmal Bauernarbeit verrichten und an deren Tisch sitzen«"

Ob diese, in der sozialistischen Ära entstandenen Untersuchungen die „Anschauungen, Gedanken, Gefühle, [...] die Mentalität des Volkes [...] ohne einmischende Deutung der Vermittler" mithilfe der Briefe herauszuarbeiten

6 Hanák 1973: 62. Übers. CS

Szenti 1988.

8 Hanák 1973: 85f.

9 Hanák 1970: 61.

10 Hanák 1973: 85f. Da der Brief im Militärarchiv Budapest in der aktuellen Pandemie-Lage für mich nicht zugänglich war, habe ich den ursprünglich deutschsprachigen - und von Hanák ins Ungarische übersetzten Brief - aus dem Ungarischen „rückübersetzen“ müssen. Für eventuelle Abweichungen im Vergleich zum Original bitte ich um Nachsicht. (CS.) 
vermochten, mag dahingestellt sein. Die Briefe aus dem Ersten Weltkrieg sind jedenfalls vielfältige Quellen für die Historiographie und sie werden in unserer Zeit nicht nur für die lokale und regionale Geschichtsschreibung ${ }^{11}$ neu entdeckt, sondern auch als Quellen, die zahlreiche sozialgeschichtlich verwertbare Aspekte liefern, u.a. zu den Geschlechterbeziehungen ${ }^{12}$ und zur Kommunikations- und Briefgeschichte überhaupt.

\section{Briefe - Produkte der Volks-Schriftlichkeit}

Für das Fach Europäische Ethnologie sind Briefe aus dem Ersten Weltkrieg unter anderem als Zeugnisse der - in der Monarchie gegebenenfalls ethnisch abweichend ausgeprägten - Volks-Schriftlichkeit beachtenswert. Die Schriftlichkeit hängt grundsätzlich mit Fragen der Bildung und Alphabetisierung der Bevölkerung zusammen.

Die Alphabetisierung der breiten Bevölkerung zeigte am Anfang des 20. Jahrhunderts in Europa ein sehr buntes Bild. Während beispielsweise das deutsche Kaiserreich im ersten Jahrzehnt des 20. Jahrhunderts den Analphabetismus offiziell als getilgt erachtete, gab es in der Monarchie einen großen Nachholbedarf, wobei innerhalb des Reiches auch noch einmal sehr große Ungleichheiten vorherrschten: Die in östlicheren Gebieten lebenden Ethnien waren schlechter gestellt als die Cisleithanier.

Für die Verhältnisse in Ungarn gilt es zu beachten, - wieder mit Hanák gesprochen:

„Die überwiegende Mehrheit der Bevölkerung war bis zum Ende des 19. Jahrhundert analphabetisch. Und wenn sich unter ihnen auch ein Schriftkundiger fand, gab es selten einen Grund zum Briefschreiben, besser gesagt, einen Anlass, von einem Schriftkundigen einen Brief schreiben zu lassen. [...] Es ist kein Zufall, dass wir unter den zahlreichen herausgegebenen Briefsammlungen nur ganz selten welche finden, die Briefe aus dem Volk enthalten. [...] Die populare Schriftlichkeit beginnt erst mit dem 20. Jahrhundert, und auch in dieser Zeit beschränkt sie sich häufig auf das Antragstellen."13

Und damit sich der oder die mehr oder weniger schriftkundige Bauer oder Bauersfrau an das Briefschreiben macht, musste das durch die Natur und durch die familiären und gesellschaftlichen Rahmen bestimmte Wertesystem

11 Pozsony 2008; Mikro- bzw. Familiengeschichte: Hauszmann 2007.

12 Ziemann 2003

13 Hanák 1973: 62. 
gesprengt werden. ${ }^{14}$ Schreiben sei für die Bauern fremd, das stellte Eugen Bonomi selbst Jahrzehnte später noch fest, der zuvor in der Zwischenkriegszeit die Schwaben des Ofner Bergland, unter anderem die Budaörser beforschte und nach dem Krieg in Deutschland ihre Briefe einsammelte. ${ }^{15}$

Welche gesetzlichen Rahmenbedingungen der Volksbildung herrschten im multiethnischen ungarischen Anteil der Monarchie? Für Ungarn wurde durch das Schulgesetz des Kultusministers József Eötvös zwar zunächst ein Grundstein gelegt (1868), da es die allgemeine Schulpflicht für die Kinder von 6-12 in die Elementarschule verordnete und für einige Wochenstunden für die 1215-jährigen in die Wiederholungsschule. Das Gesetz beachtete zugleich die Nationalitätensprachen, denn es besagte, dass ,jeder Schüler den Unterricht in seiner Muttersprache erhält" ${ }^{\text {"16. }}$. Kaum ein Jahrzehnt später jedoch wurde die ungarische Sprache in den Elementarschulen normativ eingeführt. ${ }^{17}$ Das Gesetz 26/1893 schärfte noch einmal nach; es stellte unter anderem ein Disziplinarverfahren in Aussicht, wenn der/die Lehrende eine „gegen den Staat gerichtete Richtung“"verfolge,

,insbesondere alle Handlungen, die gegen die Verfassung des Staates, deren nationalen Charakter, Einheit, Souveränität und territoriale Integrität, ferner gegen die im Gesetz bestimmte Anwendung der Sprache des Staates richten.“18

Mit dem berühmten Gesetz „Lex Apponyi“ mutierte die Sprache bzw. Sprachkenntnis der Schüler dann endgültig zu einem Messgerät von Loyalität für das Vaterland. Es besagte, dass in den nicht ungarisch-sprachigen Schulen

„die ungarische Sprache in dem Maße zu unterrichten ist, dass ein Kind nichtungarischer Muttersprache am Ende des vierten Jahrganges seine Gedanken in Wort und Schrift Ungarisch verständlich ausdrücken kann.“19

Das Gesetz delegierte seinen kompromisslosen sprachpolitischen Ansatz an die Schulen als - schwer zu realisierenden - Arbeitsauftrag. Sein $\ 17$ forderte alle Schulen aller Art und alle Lehrenden auf, ob sie staatliche Förderung erhalten oder nicht, , in den Seelen der Kinder den Geist der Loyalität für die ungarische Heimat und des Bewusstseins der Nationszugehörigkeit gedeihen

14 Hanák 1973: 62.

15 Bonomi 1965.

16 Katus 2015. Übers. CS.

17 Nr. 18/1879.

18 Katus 2015. Übers. CS.

19 \19, Gesetzartikel 27/1907. Nach Katus 2015. 
und verfestigen zu lassen“20. Darüber hinaus lässt der von Sanktionen durchdrungene Geist des Apponyi'schen Gesetztes, im Falle des Misserfolgs äußerste Härte gegen die Lehrerschaft walten.

Dieses kurze Streiflicht skizziert, in welchem Geist um die Jahrhundertwende die Kinder der breiten Bevölkerungsschichten das Lesen und Schreiben gelernt bekamen. Joachim von Puttkamer fasst zusammen: Am Vorabend des Ersten Weltkrieges erhielten die ethnisch magyarischen und nichtmagyarischen Kinder „fast durchweg eine Schulbildung, bei der die Kinder ab dem ersten Schultag an die ungarische Sprache und den ungarischen patriotischen Geist herangeführt " wurden. ${ }^{21}$ Ungeachtet dessen schritt, da das Grundschulwesen nationale Angelegenheit wurde, zugleich die Alphabetisierung in Ungarn voran:

„Bis 1910 wuchs der Anteil der Personen an der Gesamtbevölkerung Ungarns, die schreiben und lesen konnten, auf mehr als Doppelte, von 27,2\% auf 58,2\%. Für die Erfolge der Alphabetisierung spricht auch, dass der Anteil der Personen, die nur lesen, nicht aber schreiben konnten, im selben Zeitraum von $9,7 \%$ auf 2,2\% absank. Die Frauen holten auch deutlich auf. Waren 1890 noch $50,1 \%$ der männlichen, aber nur 39,0\% der weiblichen Bevölkerung des Lesens und Schreibens kundig, so waren dies zwanzig Jahre später bereits $62,0 \%$ gegenüber $54,4 \%$ ".22

Der Alphabetisierungsgrad nach Muttersprache (hier nur Ungarn und Deutsche - Letztere auch nur außerhalb von Siebenbürgen) zwischen 1890 und 1910 ergibt nach Puttkamer folgendes Bild:23

$\begin{array}{lll}\text { Gesamtbevölkerung } & 1890: 44,5 \% & 1910: 58,2 \% \\ \text { Magyaren } & 1890: 53,6 \% & 1910: 57,1 \% \\ \text { Deutsche } & 1890: 63,0 \% & 1910: 70,7 \%\end{array}$

Welchen Erfolg hatten die Elementarschulen hinsichtlich der konkreten Lese- und Schreibfähigkeit der breiten Bevölkerung? Trotz der Zahlen und der allgemein positiven Tendenzen zur Alphabetisierung gibt es ernüchternde Berichte, was die tatsächliche Schreibfähigkeit der Bevölkerung anbelangt. Etel Schwarcz beklagt 1938 in ihrem Werk „Frauenbildung und Schulwesen im 19. Jahrhundert" zu Recht, dass

\footnotetext{
Katus 2015. Übers. CS.

Puttkamer 2003: 168.

Puttkamer 2003: 168-169.

Puttkamer 2003: 169.
} 
„es im 19. Jahrhundert noch Menschen gegeben hat, die behaupteten, dass Frauen kein Recht haben, ihre Gedanken schriftlich zu äußern. In ganz Ungarn findet sich keine Schule, in der den Mädchen das fehlerfreie Briefschreiben und das im Haus nötige Rechnen beigebracht werden würde."“24

Und was die deutsche Ethnie anbelangt, beklagte Jakob Bleyer in seiner letzten Parlamentsrede am 9. Mai 1933:

„Die Jugend deutscher Muttersprache mit Volksschulausbildung kann bis zu $70 \%$ auch nicht halbwegs deutsch lesen und schreiben, die Jugend deutscher Muttersprache mit Mittelschulbildung aber kann bis zu 90\% keinen richtigen deutschen Brief schreiben, ja keinen richtigen deutschen Satz abfassen, wie man das von einem gebildeten deutschen Menschen erwarten müßte.“"25

\section{Kriegszeit und eine neue Bereitschaft zu schreiben}

Es ist davon auszugehen, dass im ausgehenden 19. Jahrhundert durch die Mobilisierung von Massen und Zersplitterung von herkömmlichen Kommunikationsgemeinschaften ein noch nie gesehener Kommunikationsbedarf entstand. Vilmos Keszeg benannte einige wichtige Stationen dieser grundsätzlichen Wandlung: die Migration, die Amerika-Auswanderung und später die Kriegsfront und Kriegsgefangenschaften. ${ }^{26}$

Der Erste Weltkrieg scheint in der Briefgeschichte der östlicheren Ethnien der Monarchie m.E. einen vergleichbaren Durchbruch erwirkt zu haben, welchen der führende Briefforscher Reinhard M. G. Nickisch für die im Kontext der folgenreichen Massenauswanderung des 19. Jahrhunderts, die in knapp hundert Jahren nahezu sechs Millionen Deutsche in die Vereinigten Staaten führte, konstatierte. Da hätten nämlich „erstmals Angehörige der Unterschicht in einer Menge, wie sie nie zuvor im deutschen Sprachraum zu registrieren gewesen war, Beiträge zur Briefliteratur geliefert ${ }^{\text {‘27. }}$. Im Zeitraum 1820 bis 1914 wird von etwa 100 Millionen Privatbriefen ausgegangen. Noch beachtlicher als die große Briefmenge ist, dass die Auswanderer-Briefe zugleich ,als Dokumente eines sozialgeschichtlich hochrelevanten Emanzipationsvorgangs zu interpretieren" seien. Diese Zeugnisse sind schriftliche

Schwarz wird hier zitiert nach: Karacs 2008: 133.

Zitiert nach: Weidlein Pannonica 1979: 405; vgl. Sonntagsblatt vom 14. Mai 1933.

Keszeg 2008: 228.

27 Nickisch 1991: 212. 
Zur Schiftlichkeit der unteren Bevölkerungsschichten...

Artikulierungen dafür, dass die Schreibenden sich „über ihre einstmalige niederdrückende soziale Lage erhoben hätten" 28 .

Die in den Ersten Weltkrieg ziehenden k.u.k. Soldaten sind in einer Epoche aufgewachsen, die reich an geschriebenen und gedruckten Buchstaben und der Faszination der bildhaften Illustration war. ${ }^{29} \mathrm{Da}$ Briefeschreiben die einzige Möglichkeit der Kommunikation war, stieg im Krieg die Bedeutung der Schriftlichkeit enorm an. Das Berichten über die Erhaltung des Lebens und der Gesundheit war ein elementares Bedürfnis - und bedurfte der eigenen Formulierung. Auch die Daheimgebliebenen mussten über sich, die Familienmitglieder und den wirtschaftlichen Stand aus eigener Feder berichten. Der Erste Weltkrieg habe, so Vilmos Keszeg, den Brief zu einer demokratischen Gattung gemacht und ihn, in die Sphäre der lebendigen Sprache und der Alltagskommunikation gehoben " 30 . Wie ein Zeitgenosse staunend offenbarte: „Im Krieg wird selbst der Einfältigste zum Schriftsteller. Es geht letztendlich um wirkliche, elementare Gefühle“31.

Offiziere und höher Gebildetere (z.B. die einjährig dienenden Freiwilligen) hatten oft regelmäßige Notizen bzw. Tagebüchereintragungen gemacht - wie sie das bereits vor dem Krieg oft auch schon gewohnt waren. Für die unteren Schichten war das Briefeschreiben, da sie, wie bereits erwähnt, nicht geschult worden waren, gegebenenfalls Neuland. Die Schriftzeugnisse selbst reflektieren manchmal diesen besonderen Umstand. Im Briefkorpus von Sándor Oláh, in dem die Korrespondenz eines frisch verheirateten Ehepaares untersucht wird, das 1914-1918 insgesamt 344 Briefe wechselte, beklagte sich die Ehefrau Rebeka Szabó bereits 1915: „oft überlege ich mir, mein Gott, wann endet die viel Briefeschreiberei, denn wir haben ja in unserem ganzen Leben bis jetzt nicht mal so viel geschrieben, wie bis jetzt seit einem Jahr" ${ }^{\text {“32. Aus }}$ den Zeilen geht es klar hervor, dass sie vor dem Ausbruch des Krieges unvergleichlich weniger Anlass gehabt hatten Briefe zu schreiben. Briefeschreiben im Krieg war und vielleicht blieb auch wohl die einzige außerhalb der Lernsituation ausgeübte schriftliche Aktivität für viele Menschen aus der breiten Bevölkerung.

Die Schriftlichkeit erlangte nichtsdestotrotz für manche Soldaten einen besonderen Stellenwert. Der Soldat Balázs Váradi aus Gesztely dokumen-

28 Nickisch 1991: 212.

29 Kiállításvezető 2008.

30 Keszeg 2008: 228.

Nagy 1915: 5, zit. nach Grund-Nagy-Szabó-Tóth 2015.

32 Wegen ihrer Sprache und ihres Sprachstils, welche nicht ins Deutsche zu übersetzten sind, sei der Originaltext angegeben: „sokszor elgondolom, Istenem lesz e vége már enek a sok levél irásnak hiszen edig életünkön keresztül sem irtunk anyit mind most egy évtöl fogva... ". Oláh o.J.: 4. 
tierte regelrecht seine eigene Korrespondenz: er zeichnete in seinem Notizbuch auf, von wem, von wo und an welchem Tag er einen Brief oder eine Postkarte in der russischen Gefangenschaft 1915-1918 erhielt. Die Auflistung findet sich unter dem Titel „Meine Korrespondenz in der Gefangen-

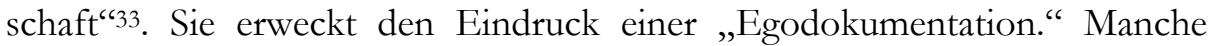
verfertigten solche Dokumentationen für den Fall ihres Todes, hoffend, dass sie durch die Kameraden die Hinterbliebenen erreichen würden.

An das Schreiben nicht gewöhnte Soldaten dürften, so die allgemeine Annahme in der Forschung (Hanák, Keszeg), gewisse Muster des Briefschreibens aus manchen (spärlichen) Quellen gekannt haben. In den Schulbüchern des 19. Jahrhunderts der Klasse 4 der Elementarschule und der weiterführenden 5.-6. Wiederholungsklassen waren Briefmuster zu finden. Diese waren jedoch durch ihre didaktische Ausrichtung ungeeignet. Gewisse Muster lieferten Groschenhefte mit Liebesgedichten, Volkskalender u.Ä., die unter den Hausbediensteten kursierten, die bei städtischen bürgerlichen Familien dienten. Auch die populären Briefratgeber, Briefsteller oder „Sekretäre", die konkrete Briefratgeber mit Formulierungs- und Rechtschreibregeln vermittelten, boten Briefbeispiele, wobei die Letzteren jedoch eher von den mittleren Schichten konsumiert wurden. (Diese Medien genossen bereits ab der Reformzeit große Popularität und haben sogar mehrere Auflagen erreicht. Viele Verlage hatten solche angeboten, da sie rentabel waren. Vorne weg die Brief-Sekretäre des erfolgreichsten Verlags des ungarndeutschen Gustav Heckenast. Seine Verlagstätigkeit ist ohnehin beachtenswert, da er in der ersten Hälfte des 19. Jh. mit seinen ungarisch-deutschen und deutschungarischen Briefmustern ein Stück weit auch das Sprachenlernen förderte freilich eher nur bei Mitgliedern des aufstrebenden Bürgertums.)

In den Dörfern waren es die lokalen Schreibkundigen, die sich auf das Briefschreiben „spezialisierten“ und sich damit etwas Zubrot verdienten, deren Schreiben bei ihren Auftraggebern eventuell als Beispiel dienten.

Die während des Krieges herausgegebene - bei diesem Problem der fehlenden Briefvorbilder als Abhilfe gedachte - Ratgeber-Reihe „Feldbriefe“ (,Tábori levelek") wurde in der Fachliteratur bereits kritisch vorgestellt. ${ }^{34}$ Es handelte sich um eine Reihe von 16 Heften, die in zahlreichen Exemplaren im Umlauf waren. Herausgeber István Toma sowie die meisten Autoren waren überwiegend Geistliche. Die ersten vier Bände sind Anleitungen zum Briefeschreiben an die Ehefrau, an die Kinder, an die Mutter und an das

33 Csorba 1985

34 Csíki 2017. 
Heimatdorf. ${ }^{35}$ Wie Csíki feststellt, waren diese Texte kaum hilfreich. Eher hatten diese Anleitungen zum Ziel, die „richtige“, d.h. erwünschte Denkweise, Einstellung und das richtige Verhalten zu suggerieren. Der erste Brief, der an die Ehefrau gehen soll, schreibt vor, wie sich die „echte ungarische Ehefrau" in der Kriegszeit zu verhalten habe: sie soll nicht verzagen, sondern ihren Mann ermutigen, in den Krieg zu ziehen, sogar freiwillig, und sie soll standhaft dessen Aufgaben in der Hauswirtschaft übernehmen. Die Aufopferung sei nötig, da Ungarn im Existenzkampf der anderen Länder gefährdet sei. Der Topos vom christlichen Ungarn, das jahrhundertelang als Schutzbastion des Christentums diente, wird wieder aktualisiert und gekoppelt an eine naive Charakterologie. Ungarn müsse nicht nur sich selbst verteidigen, sondern „die christliche Kultur gegen die slawische Barbarei und die griechisch-orthodoxe Abtrünnigkeit, mit welchen die Serben und Russen Europa verschütten“, dabei sei es ,,beschämend, dass das einst so rein katholische Frankreich und das christliche, aber ketzerische England sich mit

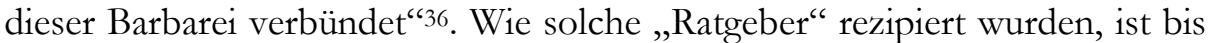
dato wenig bekannt. Csíki dürfte jedenfalls in der Annahme richtigliegen, dass es unwahrscheinlich ist, dass in den Schießscharten abendlich über beispielhafte historische Romanhelden gesprochen worden wäre.

\section{Kriegsbriefe und Briefsprache}

Im siebenbürgischen Dorf Vargyas versuchte die Ehefrau Julianna Tóth in ihrem Brief am 26. Februar 1916 ihren Mann zu überreden, für dessen Beurlaubung mithilfe des Notars einen Antrag für stellen zu lassen:

„Schreib ob ich mit dem Herrn Notar sprechen soll dass er einen Antrag machen soll was er dazu sagt ob man dich nicht für einige Woche nach Hause lassen würde schreib ob ich mit dem Herrn Notar veranlassen soll [...] Für Jóska Mátyás hat er auch einen gemacht mir macht er erst recht einen.“"37

Der obige Brief aus dem Briefkorpus von Juliánna Kokó belegt, dass sich private Schriftpraxis und Auftragspraxis (d.h. das Schreiben jemand Schrift-

35 Domonkos 1914; Kertész 1914; Kriston 1914; Radványi 1914; Vass 1914.

36 Kertész 1914: 5-8, hier nach Csíki 2017. Übers. CS.

37 Der Originaltext von Julianna Tóth: „...irrd meg hogyha én jegyző ural beszélnék hát és kérelmet csinálna hát mit szolheza nem eresztenének. e haza egypár hétre téged hát ird meg hogy csináltasak-e jegyzoóural én ha irod bát beszélek [...] Mátyás Jóskának is csinált és nekem még ugyan csinál..." Kokó 1999. 
kundigen überlassen) sich überlappen. Die kurze Passage zeigt auch klare sprachliche Merkmale der in Schrift gegossenen Mündlichkeit: der Brief folgt eher dem Fluss der gesprochenen Sprache als der der Schriftsprache. Eine korrekte, verständliche Wiedergabe von Ereignissen und vom Erlebten, geschweige denn die Emotionalität und persönlichen seelischen Befindlichkeiten, in Schrift zu formulieren, erforderte eine hohe Schreibkompetenz, die viele Menschen, insbesondere in den unteren Bevölkerungsschichten wohl kaum besaßen. Die eigentlichen Schreibregeln - sofern man sie überhaupt kannte - blieben außer Beachtung. Der Brief „entledigte sich der Schreibregeln" 38 . So richtungsweisend diese Feststellung von Vilmos Keszeg ist, so wenig sind jedoch bis dato die Untersuchungen, die diese von den Regeln entledigte Schriftsprache analysieren, ${ }^{39}$ wie das Juliánna Kokó und Sándor Oláh für den siebenbürgischen und Grund-Nagy-Szabó-Tóth für den ungarischen Sprachraum bei ihren jeweiligen Briefkorpora leisten.

Nichtsdestotrotz lohnt sich die sprachliche Analyse von Kriegsbriefen unter anderem auch für die Erforschung von mehrsprachigem Sprachgebrauch: Der 18-jährig in den Krieg ziehende Zoltán Hirscher korrespondierte in zwei Sprachen. ${ }^{40}$ Er schrieb seinem Vater in deutscher Sprache (4 Briefe und 17 Postkarten) und seiner Mutter in ungarischer (33 Briefe und 11 Postkarten).

In den obigen Ausführungen wurden Briefe aus dem Ersten Weltkrieg vor allem als Zeugnisse der Volks-Schriftlichkeit betrachtet. Wie wir gesehen haben: die ungarisch-sprachige (volkskundliche) Literatur liefert zahlreiche Beobachtungen zur Schriftlichkeit der breiteren Bevölkerungsschichten um die Zeit des Ersten Weltkrieges. Grundlage für diesen Beitrag mussten - in aktuell mangelnder Zugänglichkeit der Quellen - sekundäre Quellen bilden.

\section{Literatur}

BONOMI, Eugen

1965 [1961/1964] Mein Briefwechsel mit heimatvertriebenen Deutschen aus dem Ofner Bergland / Ungarn. Württembergisches Jabrbuch für Volkskunde. 64. 157-187.

Keszeg 2008

Nagy 2015: 835.

40 Grund-Nagy-Szabó-Tóth 2015. 
Zur Schiftlichkeit der unteren Bevölkerungsschichten...

CSÍKI, Tamás

2017 Hogyan írjunk levelet háborúban? Útmutató „harcosok“ számára. In Albert Zsolt Jakab - András Vajda (Hg.): Aranyhíd. 779-787. Kolozsvár: BBTE Magyar Néprajz és Antropológia Intézet - Erdélyi MúzeCSORBA, Csaba um-Egyesület - Kriza János Néprajzi Társaság

1986 A gesztelyi Váradi Balázs feljegyzései hadifogságban. A Miskolci Hermann Ottó Múzeum Közleményei. 24. 93-96.

DIMÉNY HASZMANN, Orsolya

2007 Írott emlékek az Első Világháborúból. Acta Siculica. 727-738.

DEIGNER, Leopold

2011 Családunk történetét szenvedélyesen kutatom. Die Ahnenforschung bereitet mir eine Freude. In Klára Steinhauser (Hg.): Régi Budaörsi Családok = Alte Budaörser Familien III. 22-23. Budaörs: Német Nemzetiségi Önkormányzat

DOMONKOS István

1914 A harcos levele falujához. Budapest: Élet

GRUND, Anna Borbála - NAGY, Gabriella - SZABÓ, Fanni - TÓTH, Barbara

2015 A Nagy Háború nyelvi lenyomata. Hadtörténelmi Közlemények. 128. (3). 830-851.

HANÁK, Péter

1970 Die Volksmeinung während der letzten Kriegsjahre in ÖsterreichUngarn. In: Richard Georg Plaschka - Karlheinz Mack (Hg.): Die Auflösung des Habsburgerreiches Zusammenbruch und Neuorientierung im Donauraum (Schriftenreihe des österreichischen Ost- und Südosteuropa-Instituts 3). 58-66. München: Oldenbourg

1973 Népi levelek azt első világháborúból. Valóság. XVI (3). 62-87.

KARACS, Zsigmond

2008 Karacs Teréz és a 19. századi nőnevelés. Budapesti Históriák - a 2008. évi előadások. A Budapesti Históriák előadásainak szerkesztett anyagai. http://bpht.hu/historiak/102.pdf -20.04 .2020$

KATUS, László

2015 A Lex Apponyi. Rubiconline. 2015/2.

http://www.rubicon.hu/magyar/oldalak/onlineplusz $20152 \mathrm{szam} /$ $-20.04 .2020$

KERTÉSZ Kálmán

1914 A barcos levele feleségéhez. Budapest: Élet

KESZEG, Vilmos

2008 Alfabetizáció, irásszokások, populáris irásbeliség. Kolozsvár: Kriza János Néprajzi Társaság 
Kiállításvezető

2008 A Nagy Háború írásban és képben 1918-2008 c. vándorkiállitáshoz. Budapest: HM Hadtörténeti Intézet és Múzeum https://docplayer.hu/1257586-Tartalom-bevezeto-2-kiallitasvezeto-anagy-haboru-irasban-es-kepben-c-vandorkiallitashoz.html - 20.04.2020

KOKÓ, Juliánna

1999 Egy vargyasi család levelezése az első világháborúban. In Vilmos Keszeg (Hg.): Írás, írott kultúra, folk.lore. 240-265. Kriza János Néprajzi Társaság Évkönyve. 7.

KRISTON Endre

1914 A harcos levele gyermekeihez. Budapest: Élet

NICKISCH, Reinhard M. G.

1991 Brief. Stuttgart: Metzer

OLÁH, Sándor

o.J. Nyelvi sztereotípiák egy házaspár első világháborús levelezésében https://adoc.tips/olah-sandor-nyelvi-sztereotipiak-egy-hazaspar-elsvilaghabor.html -15.04 .2020$

POZSONY, Ferenc

2008 Az írott források szerepe az elsö világháború lokális eseményeinek vizsgálatában. 1916 Zabolán. In Albert Zsolt Jakab - András Vajda (Hg.): Aranyhíd. 789-799. Kolozsvár: BBTE Magyar Néprajz és Antropológia Intézet - Erdélyi Múzeum-Egyesület - Kriza János Néprajzi Társaság

PUTTKAMER, Joachim von

2003 Schulalltag und nationale Integration in Ungarn. Slowaken, Rumänen und Siebenbürger Sachsen in der Auseinandersetzung mit der ungarischen Staatsidee 1867-1914. München: Oldenbourg

RADVÁNYI Kálmán

1914 A barcos levele édesanyjához. Budapest: Élet

SZENTI, Tibor

$1988 V$ Vér és pezsgö. Harctéri naplók, visszaemlékez̧ések, frontversek, tábori és családi levelek az elsö világháborúból. Budapest: Magvető

VASS József

1914 A küzdö hösökhöz. Budapest: Élet

WEIDLEIN, Johann

1979 Pannonica. Ausgewählte Abhandlungen zur Sprach-und Geschichtsforschung der Donauschwaben und der Magyaren. Schorndorf

ZIEMANN, Benjamin

2003 Geschlechterbeziehungen in deutschen Feldpostbriefen des Ersten Weltkrieges. In Christa Hämmerle - Edith Sauer (Hg.): Briefkulturen und ibr Geschlecht. Zur Geschichte der privaten Korrespondenz, vom 16. Jahrhundert bis heute. 261-282. Wien-Köln-Weimar: Böhlau 